\section{Equilibration of Hemoglobin Concentration after Transfusion in Medical Inpatients Not Actively Bleeding}

Andrew R. Wiesen, MD; Duane R. Hospenthal, MD, PhD; John C. Byrd, MD; Kevin L. Glass, MD; Robin S. Howard, MA; and Louis F. Diehl, MD

Ann Intern Med. 1994;121:278-280.

More than 12 million units of packed erythrocytes are transfused annually $(1,2)$. Because blood products became widely used after World War II, hundreds of millions of units have been given (1-4). Major textbooks state that an increase of $10 \mathrm{~g} / \mathrm{L}(1 \mathrm{~g} / \mathrm{dL})$ of hemoglobin is expected per unit of blood transfused (5-10). Authors (5, 8 , 11) have implied that after transfusion, the rate at which the hemoglobin concentration equilibrates takes about 24 hours, but the supporting evidence is scant. The ability to rapidly determine the increase in hemoglobin levels after transfusion is important in managing outpatients and acutely ill patients. A standard time to measure the hemoglobin levels would save unnecessary blood draws.

To clarify these issues, we did a prospective study of medical inpatients at a tertiary care medical center to determine the amount of increase in hemoglobin levels after transfusion and the rapidity of equilibration. Hemoglobin levels rather than hematocrit levels were chosen because they are directly measured, not calculated (12).

\section{Methods \\ Participants}

Patients on the general medicine service of a 700-bed teaching hospital from January to June 1993 were eligible if they were to receive a 2-unit packed erythrocyte transfusion. Exclusion criteria included age younger than 18 years, recent active bleeding, and inability to give a written informed consent. Hemoglobin concentration was measured at 15 minutes, 1 hour, 2 hours, and 24 hours after the end of the transfusion.

\section{Experimental Measurements}

Blood was drawn in standard 2.5 or $3 \mathrm{~mL}$ Vacutainer blood tubes (Bectin-Dickinson Company; Rutherford, New Jersey), and complete blood counts were measured on Coulter S plus STKR machines (Coulter Electronics; Hialeah, Florida) using standard laboratory methods. Patients were interviewed and records were reviewed for age, height, and weight data; history of congestive heart failure; use of diuretic agents; and presence of fever.

On the basis of data from a previous study (13), it was assumed that the change in hemoglobin over 24 hours would be 18 $\pm 8 \mathrm{~g} / \mathrm{L}$ for a 2-unit transfusion. Controlling the probability of a type I error at $\alpha=0.05$, a sample of 34 patients would yield $80 \%$

From the Walter Reed Army Medical Center, Washington, D.C. For current author addresses, see end of text. power to detect a change in hemoglobin of 0.5 SDs or a $4 \mathrm{~g} / \mathrm{L}$ change in hemoglobin levels.

\section{Statistical Methods}

The mean change in hemoglobin levels is presented together with $95 \%$ confidence intervals. The change in hemoglobin concentration over time was examined by repeated measures analysis of variance using BMPD v. 7.0 (BMDP Statistical; Los Angeles, California). Sex, age, weight, body surface area, estimated blood volume, presence of a temperature greater than $38^{\circ} \mathrm{C}$, use of diuretic agents, history of congestive heart failure, and transfusion time were each included in the analysis of variance to explore possible confounding effects on hemoglobin equilibration. Creatinine clearance (14) and blood volumes (15) were estimated using published formulas, and body surface area was calculated using standard nomograms. The association between the 24-hour change in hemoglobin levels and continuous demographic and clinical factors was examined using the Pearson correlation coefficient (P). A two-sided $P$ value of 0.05 or less was considered significant.

\section{Results}

Fifty-two patients were interviewed for inclusion in the study. Six patients withdrew from the study because they received a transfusion other than a 2 -unit transfusion, and two patients withdrew because they were not transfused. Five patients enrolled in the study twice. Only the first transfusion in these patients was analyzed. Thus, 39 patients were included in the data analysis.

Study patient characteristics are summarized in Table 1 . The mean hemoglobin concentration increased by $20 \mathrm{~g} / \mathrm{L}$ (95\% CI, 17 to $22 \mathrm{~g} / \mathrm{L}$ ) during 24 hours (Figure 1). Hemoglobin levels before transfusion were lower than levels after transfusion $(P<0.001)$, but no significant differences were noted among the 15-minute, 1-hour, 2 -hour, and 24-hour hemoglobin values $(P=0.82)$. The change in hemoglobin concentration between 15 minutes and 24 hours ranged from $22 \mathrm{~g} / \mathrm{L}$ to $20 \mathrm{~g} / \mathrm{L}(-2.2 \mathrm{~g} / \mathrm{dL}$ to $2.0 \mathrm{~g} / \mathrm{dL})$. Twenty-three $(59 \%)$ of the 39 patients had hemoglobin concentrations within $6.6 \mathrm{~g} / \mathrm{L}$ of their 24-hour value at 15 minutes and $35(90 \%)$ had concentrations within $10 \mathrm{~g} / \mathrm{L}$ (Figure 2). A clinically significant change in hemoglobin level is generally considered to be 6.6 to 10 g/L (12).

Age, sex, weight, body surface area, estimated blood volume, history of congestive heart failure, use of diuretic agents, creatinine clearance of less than $30 \mathrm{~mL} / \mathrm{min}$, pres-

\section{Table 1. Patient Characteristics}

\begin{tabular}{lc}
\hline Characteristic & \multicolumn{1}{c}{ Value } \\
\hline Age (range), $y$ & $52.6(26$ to 81$)$ \\
Men/women, $n$ & $23 / 16$ \\
Weight (range), $k g$ & $70.0(45.5$ to 104.5$)$ \\
Body surface area (range), $m^{2}$ & $1.81(1.46$ to 2.23$)$ \\
Estimated blood volume (range), $L$ & $4.54(3.25$ to 5.94$)$ \\
History of congestive heart failure, $n$ (\%) & $4(10)$ \\
Calculated creatinine clearance $<30$ & $2(5)$ \\
$\quad$ mL/min, $n$ (\%) & $9(23)$ \\
Diuretic use near transfusion, $n$ (\%) & $10(26)$ \\
Fever near transfusion, $n$ (\%) & $430(183$ to 730$)$ \\
Duration of transfusion (range), $\min$ &
\end{tabular}


ence of fever in the near-transfusion period, and duration of transfusion were not found to influence hemoglobin equilibration (data not shown). The correlation between the 24-hour change in hemoglobin level and weight $(r=$ $-0.16)$, blood volume $(r=-0.22)$, and transfusion time $(r=0.20)$ was not statistically significant.

\section{Discussion}

In 1964, Huber and colleagues (13) found the average increase in hemoglobin concentrations was $0.9 \pm 0.1$ $\mathrm{g} / \mathrm{dL}$ ) in a study of 16 adult patients with mild splenomegaly. Our study confirms this finding.

No studies exist in adults assessing the time course of hemoglobin concentration after transfusion. Studies in children have yielded conflicting results. An early study (16) involving 12 children showed that the hemoglobin concentration at 24 hours was approximately $110 \%$ of the value immediately after transfusion. A more recent study of 14 neonates (17) showed that hematocrit levels measured at 1 and 6 hours after transfusion were statistically equivalent. It has been implied that blood volume is expanded immediately after transfusion and does not return to normal for 24 hours (14). In fact, it was shown that after large-volume saline infusions, most excess fluid is eliminated from the intravascular space in minutes (18). Thus, erythrocyte transfusion should cause a minimal, transient expansion in blood volume.

In 1988, O'Connell and colleagues (19) did an equilibration study with platelets that showed that the platelet counts 10 and 60 minutes after transfusion were equivalent, and this enabled the investigators to decrease clinic encounter time. Our study shows that the hemoglobin level 15 minutes after transfusion is nearly identical to the 24-hour level in patients who are not actively bleeding; it thus shows the value of rapid assessment. None of the clinical factors measured were found to influence hemo-

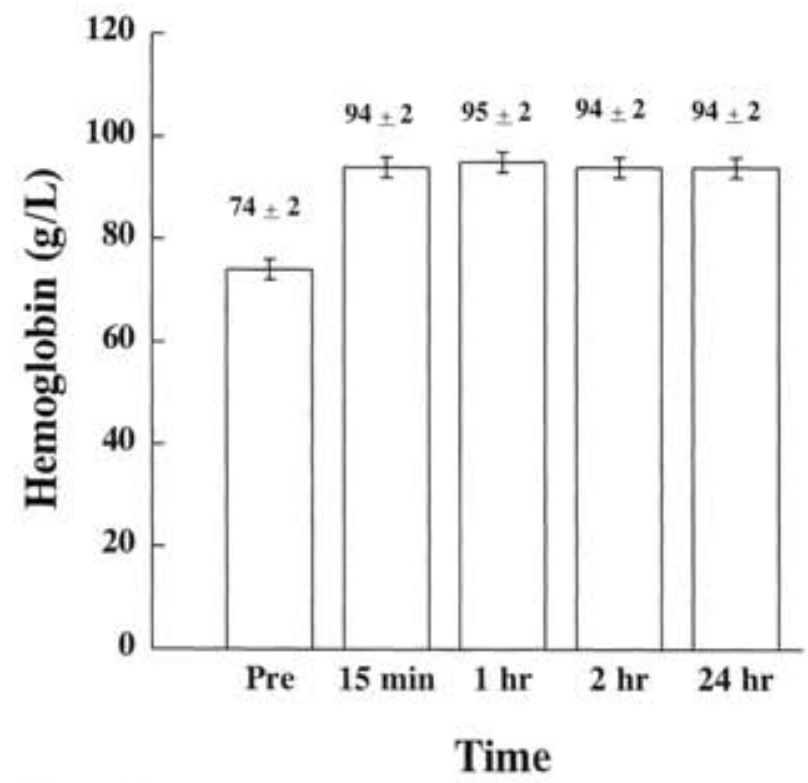

Figure 1. Increase in hemoglobin concentration after transfusion. The increase in hemoglobin concentration after a 2-unit transfusion of packed erythrocytes was $20 \pm 2 \mathrm{~g} / \mathrm{L}(P<0.001)$. Values are expressed as mean $\pm \mathrm{SE}$; error bars represent the SE.

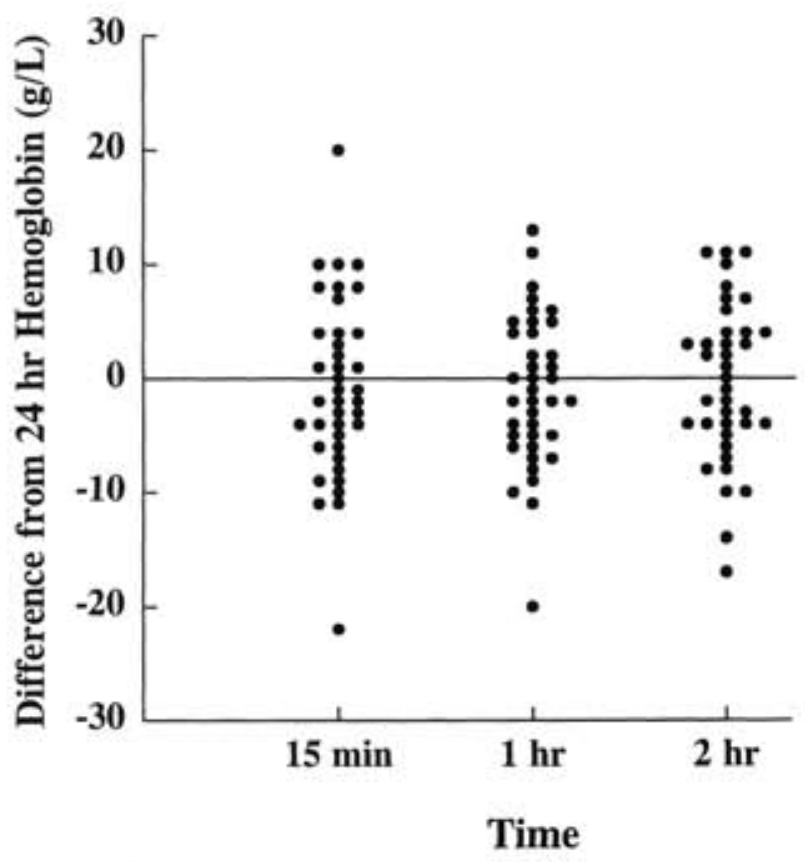

Figure 2. Change in hemoglobin concentration over time. Differences in hemoglobin concentrations between 24 hours after transfusion and 15 minutes, 1 hour, and 2 hours after a 2-unit transfusion of packed erythrocytes.

globin equilibration. Although no relation was found for renal dysfunction or congestive heart failure, such a relation may be beyond the detection power of this study. Other limitations of this study include the fact that we examined only medical inpatients and excluded persons with active or recent bleeding (because an equilibration experiment requires a steady state).

We conclude that transfusion with 1 unit of packed erythrocytes increases the hemoglobin level an average of $10 \mathrm{~g} / \mathrm{L}(1.0 \mathrm{~g} / \mathrm{dL})$ and that hemoglobin measurements made 15 minutes after transfusion reflect steady state values. Such measurements should be of great value in decreasing patient waiting time after outpatient blood transfusions and decreasing the need to repeat blood tests in 24 to 48 hours.

The opinions or assertions contained herein are the private views of the authors and are not to be construed as official or as reflecting the views of the Department of the Army or the Department of Defense.

Requests for Reprints: Andrew R. Wiesen, MD, Internal Medicine Clinic, Lister Army Community Hospital, Ft. Rucker, AL 36362.

Cument Author Addresses: Dr. Weisen: Internal Medicine Clinic, Lister Army Community Hospital, Ft. Rucker, AL 36362.

Drs. Hospenthel and Glass: Department of Medicine, 121st Evacuation Hospital, Seoul, Korea APO, AP 96205.

Drs. Byrd and Diehl: Department of Hematology, Walter Reed Army Medical Center, Washington, DC 20307-5001.

Ms. Howard: Department of Clinical Investigation, Walter Reed Army Medical Center, Washington, DC 20307-5001.

\section{References}

1. Surgenor DM, Wallace EL, Hao HS, Chapman RH. Collection and transfusion of blood in the United States, 1982-1988. N Engl J Med. 1990:322:1646-51.

2. Wallace EL, Surgenor DM, Hao HS, An J, Chapman RH, Churchill Wh. Collection and transfusion of blood and blood components in the United States, 1989. Transfusion. 1993;33:139-44.

3. McCullough J. The nation's changing blood supply system. JAMA. 1993:269:2239-45. 
4. Grove-Rasmussen M, Lesses MF, Anstall HB. Transfusion therapy. N Engl J Med. 1961;264:1034-88.

5. Barnes A. Blood component therapy. In: Bick RL, ed. Hematology Clinical and Laboratory Practice. St. Louis: Mosby-Year Book; 1993: 1653.

6. Simpson MB. Transfusion therapy for hematologic diseases, In: Koepke JA, ed. Laboratory Hematology. New York: Churchill Living. stone; 1984:1149.

7. Simon TL. Red cell transfusion. In: Rossi EC, Simon TL, Moss GS, eds. Principles of Transfusion Medicine. Baltimore: Williams \& Wilkins; 1991:97.

8. Jones J. The transfusion of red cells. In: Mollison PL, Engelfreit CP, Contreras M, eds. Blood Transfusion in Clinical Medicine, 9th ed. Oxford: Blackwell Scientific Publications; 1993:423.

9. Johnston MF. Blood component therapy. In: Rutman RC, Miller WV, eds. Transfusion Therapy, Principles and Procedures. $2 \mathrm{~d}$ ed. Rockville: Aspen; 1985:35.

10. Keeling RP, Alberico TA. Transfusion therapy. In: Thorup OA Jr, ed. Fundamentals of Clinical Hematology. Philadelphia: W.B. Saunders; 1987:932.

11. Widmann FK, ed. Technical Manual of the American Association of Blood Banks. 9th ed. 1985:7-8.
12. Wintrobe MM. Clinical Hematology. 8th ed. Philadelphia: Lea and Febiger; 1981:8.

13. Huber H, Lewis SM, Szur L. The influence of anaemia, polycythaemia and splenomegaly on the relationship between venous hematocrit and red-cell volume, Brit J Haemat. 1964;10-567-75.

14. Rovin BH. Renal diseases. In: Dunagan WC, Ridner ML eds. Manual of Medical Therapeutics. 26th ed. Boston: Little, Brown; 1989:221.

15. Nadler SB, Hidalgo JU, Bloch T. Prediction of blood volume in normal human adults. Surgery. 1961:51:224-32.

16. Mollison PL. The survival of transfused erythrocytes with special reference to cases of acquired haemolytic anaemia. Clin Sci. 1947;6:137 72.

17. Sekhsaria $\mathbf{S}$, Fomufod A. Readjustment of hematocrit values after packed red cell transfusion in the neonate. J Perinatol. 1991;11:161-3.

18. Greenfield RH, Bessen HA, Henneman PL. Effect of crystalloid infusion on hematocrit and intravascular volume in healthy, nonbleeding subjects. Ann Emerg Med. 1989;18-51-5.

19. O'Connell B, Lee EJ, Sehiffer CA. The value of 10-minute posttransfusion platelet counts. Transfusion. 1988,28:66-7.

(C) 1994 American College of Physicians 